\title{
Maturity of the Adrenal Cortex in Very Preterm Infants Is Related to Gestational Age
}

\author{
ROEL J. BOLT, MIRJAM M. VAN WEISSENBRUCH, CORRIE POPP-SNIJDERS, FRED G.J. SWEEP, \\ HARRY N. LAFEBER, AND HENRIETTE A. DELEMARRE-VAN DE WAAL \\ Departments of Pediatrics (R.J.B., M.M.v.W., H.N.L., H.A.D-v.d.W.) and Clinical Chemistry and \\ Endocrinology (C.P.-S.), VU University Medical Center, P.O. Box 7057, NL-1007 MB Amsterdam, The \\ Netherlands; and Department of Chemical Endocrinology (F.G.J.S.), University Medical Center, St. \\ Radboud, P.O. Box NL, Nijmegen, The Netherlands
} \begin{abstract}
ABST
To study the maturity of the adrenal cortex in preterms born
before 33 wk of gestation, basal levels of cortisol and cortisone and the cortisol and 17-hydroxyprogesterone (17-OHP) response to $1 \mu \mathrm{g} / \mathrm{kg}$ adrenocorticotropic hormone stimulation were measured in 24 appropriate-for-gestational age preterm infants (26-33 wk; 690-1985 g). Gestational age influenced the response of cortisol, 17-OHP, and the ratio between cortisol/17-OHP in the studied infants. In preterms born $<30$ wk of gestation, levels of cortisol, and the ratio between cortisol/17-OHP were lower compared with preterms born between 30 and 33 wk. Levels of cortisone were higher in preterms born $<30 \mathrm{wk}$, suggesting a lower activity of $11 \beta$-hydroxysteroid dehydrogenase that may be related to maturity as well. These findings indicate that the
\end{abstract}

adrenal cortex function in preterm infants is closely related to the duration of gestation and may be important in neonatal morbidity. (Pediatr Res 52: 405-410, 2002)

Abbreviations
$11 \beta$ HSD, 11 $\beta$-hydroxysteroid dehydrogenase
17 OHP, 17-hydroxyprogesterone
ACTH, adrenocorticotropic hormone
AGA, appropriate, for-gestational age
DHEAS, dehydroepiandrosterone sulfate
HPA axis, hypothalamic-pituitary-adrenal axis
SGA, small-for-gestational age

To evaluate the adrenal function the plasma cortisol response to i.v. administered ACTH is a common screening test. In general, $250 \mu \mathrm{g}$ synthetic ACTH is given as a bolus dose to stimulate cortisol release from the adrenal cortex, in adults as well as children as described by Wood et al. in 1965 (8). This supra-physiologic dose is much higher than required to produce a maximal adrenal response and could elicit an appropriate response despite of adrenal insufficiency $(9,10)$. Therefore, a lower dose of ACTH has been proposed to study the adrenal function.

We hypothesize that differences in the maturity of the HPAaxis related to gestational age can be observed in the levels of hormones produced by the adrenal cortex and the adrenal response to ACTH in preterm infants of different gestational ages. The objective was to study basal levels of glucocorticoids and to establish the effect of stimulation of the adrenal cortex with ACTH in very preterm infants at the end of the 1 st week of life.

\section{PATIENTS AND METHODS}

Patients. The study group consisted of 24 preterm infants with gestational ages ranging from 26 to 33 wk and birth weights ranging from 690 to $1985 \mathrm{~g}$. Patients admitted to our
Correspondence: Roel J. Bolt, Department of Pediatrics, VU University Medical Center, P.O. Box 7057, NL-1007 MB Amsterdam, The Netherlands; E-mail: roel.bolt@vumc.nl

DOI: 10.1203/01.PDR.0000022343.57970.CF 
neonatal intensive care unit were eligible to be enrolled if they were appropriate for gestational age (i.e. birth weight SD score adjusted for gestational age, parity, and sex between -2 SD and +2 SD according to a Dutch reference population) (11). In addition, all patients required respiratory support (high frequency ventilation, conventional mechanical ventilation, or continuous positive airway pressure) during the 1st week of life, and had no major congenital anomalies. All infants to be studied had an arterial and/or venous indwelling catheter, and had not received postnatal treatment with corticosteroids. Infants did not receive packed cell transfusions within $2 \mathrm{~d}$ of the test. Results were analyzed using gestational age as a continuous variable. However, based on clinical observations that preterm infants born before $30 \mathrm{wk}$ of gestation have a higher risk for the development of chronic lung disease compared with infants born after $30 \mathrm{wk}$ of gestation (6), patients were also subdivided into two groups. Group A consisted of 13 patients with gestational ages ranging from 26 to 29 wk and group B consisted of 11 patients with gestational ages ranging from 30 to $33 \mathrm{wk}$. Clinical data of both groups are summarized in Table 1. Most preterm infants (21 out of 24 infants) received antenatal glucocorticoid treatment (i.e. 2 doses of $11.4 \mathrm{mg}$ betamethasone in $48 \mathrm{~h}$ at weekly intervals). Two infants were born before the second dose of antenatal steroids was administered, and one infants was born within $24 \mathrm{~h}$ after the second dose of antenatal steroids. Three infants received a second course and one infant a third course of antenatal steroids. None of the patients showed signs of birth asphyxia. Infants in group A required comparable levels of oxygen during the 1st week, but the duration of mechanical ventilation and hospital stay was significantly longer compared with infants in group B (Table 1). Written informed consent was obtained from all parents. The study protocol was approved by the Ethics Committee of the VU University Medical Center, Amsterdam, The Netherlands.

Testing protocol. To minimize the possible influences of birth associated stress and antenatal steroid treatment due to premature labor, ACTH tests were performed not sooner than the 5th to 10th day of life between 08:00 $\mathrm{h}$ and 09:00 h. Infants underwent the ACTH test only when they were clinically stable

Table 1. Clinical characteristics of the study population $(\text { mean } \pm S D)^{\mathcal{S}}$

\begin{tabular}{lll}
\hline & \multicolumn{1}{c}{ Group A $^{\circ}$} & \multicolumn{1}{c}{ Group B } \\
\hline Gender & 7 male/6 female & 6 male $/ 5$ female \\
Gestational age (weeks)* & $28.1 \pm 1.2$ & $30.9 \pm 1.1$ \\
Birth weight (grams)* & $996 \pm 178$ & $1471 \pm 294$ \\
Birth length (cm)* & $35.8 \pm 1.6$ & $40.1 \pm 2.7$ \\
Head circumference (cm)* & $26.1 \pm 1.9$ & $28.9 \pm 1.6$ \\
Antenatal steroids & $12 / 13$ & $9 / 11$ \\
Apgar score at 5 min $<5$ & $0 / 13$ & $0 / 11$ \\
Oxygen during first week (median & $31(21-57)$ & $30(22-43)$ \\
$\quad$ (range) \% of inspired air) & & \\
Days on mechanical ventilation* & $19(9-38)$ & $9(1-29)$ \\
$\quad$ median (range) & & \\
Length of stay in hospital (days)* & $76.9 \pm 15.0$ & $51.7 \pm 22.1$
\end{tabular}

\footnotetext{
${ }^{\S}$ Results are presented as the mean \pm SD.

${ }^{\circ}$ Group A: gestational age $<30$ weeks $(n=13)$; group B: gestational age $30-33$ weeks $(n=11)$. Asterisks $(*)$ indicate statistical difference between
} both groups $(p<0.05)$. and did not show any clinical or laboratory signs of infection. After basal blood sampling, $1 \mu \mathrm{g}$ per kilogram body weight (1 $\mu \mathrm{g} / \mathrm{kg}$ ) ACTH (tetracosactide, Synacthen, Ciba-Geigy, The Netherlands) was administered i.v. (without the use of additional plastic tubing connections and after flushing the heparinized indwelling i.v. cannula with $\mathrm{NaCl} 0.9 \%$ ). The dose was obtained by dilution of ACTH in normal saline and prepared within 30 min before administration. Blood samples (each 0.3 milliliter) were withdrawn just before, as well as 30 and $60 \mathrm{~min}$ after i.v. ACTH administration for determination of cortisol and 17-hydroxyprogesterone (17-OHP). Because of limited blood sample volumes in preterm infants, we have carefully chosen only to determine cortisol and 17-OHP. The latter was chosen as a determinant of the capacity of the adrenal cortex to convert steroid precursors, while cortisol was chosen as the final product of glucocorticoid synthesis. In addition, the activity of $11 \beta$-hydroxysteroid dehydrogenase $(11 \beta$-HSD) in the adrenal cortex of preterm infants was indirectly studied by the determination of cortisol and cortisone in a blood sample taken at $08: 00 \mathrm{~h} 1$ to $2 \mathrm{~d}$ before the ACTH test.

Hormone assays. Blood samples were allowed to clot for 15 min at room temperature. Serum was separated and stored at $-20^{\circ} \mathrm{C}$ until analysis. Serum cortisol was determined in duplicate by RIA (Coat-A-Count, DPC, Los Angeles, U.S.A.). Serum 17-OHP was determined in duplicate by a competitive ELISA (DRG Instruments, Marburg, Germany) directly in serum without an extraction step because of limited blood sample volumes in preterm infants. Therefore, steroids originating from the fetal zone of the (immature) adrenal cortex, such as 17-hydroxypregnenolonesulfate, were not removed and could contribute to the 17-OHP values because of crossreactivity (12). However, the levels of cross-reaction of other steroids, including DHEAS and cortisol, were less than $0.05 \%$, with the exception of 11-desoxycortisol (1.4\%) and progesterone $(1.2 \%)$. The detection limit was $30 \mathrm{nmol} / \mathrm{L}$ for cortisol and $0.5 \mathrm{nmol} / \mathrm{L}$ for $17-\mathrm{OHP}$. The intraassay and interassay coefficients of variation were $5 \%$ and $7 \%$ at a cortisol level of 550 $\mathrm{nmol} / \mathrm{L}, 4 \%$ and $7 \%$ at a cortisol level of $1000 \mathrm{nmol} / \mathrm{L}$. For 17-OHP the intraassay and interassay coefficients of variation were $8 \%$ and $16 \%$ at a $17-\mathrm{OHP}$ level of $3 \mathrm{nmol} / \mathrm{L}$, and $4 \%$ and $11 \%$ at a $17-\mathrm{OHP}$ level of $9 \mathrm{nmol} / \mathrm{L}$. The intra-assay coefficient of variation was $5 \%$ at a $17-\mathrm{OHP}$ level of $20 \mathrm{nmol} / \mathrm{L}$. In addition, cortisol and cortisone levels were determined by RIA after extraction and paperchromatographic purification, as described elsewhere (13). The detection limit using this methods was $5 \mathrm{nmol} / \mathrm{L}$ for cortisol and $1.3 \mathrm{nmol} / \mathrm{L}$ for cortisone. Using this technique the intraassay and interassay coefficients of variation were $5 \%$ and $8 \%$ for cortisol at a level of 0.27 $\mu \mathrm{mol} / \mathrm{L}$, and $6 \%$ and $11 \%$ for cortisone at a level of $48 \mathrm{nmol} / \mathrm{L}$.

Statistical analysis. Results are presented as the mean \pm SEM unless indicated otherwise. The baseline level was defined as the concentration at $0 \mathrm{~min}$. Group differences were analyzed with $t$ tests, Mann-Whitney $\mathrm{U}$ tests, and $\chi^{2}$ tests where appropriate. For related samples, results were analyzed using repeated measures analysis of covariance (ANCOVA) with gestational age as covariable. To study the hypothesis that the postnatal age (5-10 d of life) influences the adrenal response, the analysis was repeated with postnatal age as an 
additional covariable. Within-group differences and groups differences were analyzed with repeated measures analysis of variance (ANOVA). Significance was assumed when the probability value exceeded $95 \%(p<0.05)$.

\section{RESULTS}

Response of cortisol. The overall effect of gestational age on cortisol showed a trend toward higher cortisol responses with increasing gestational age (ANCOVA; $p=0.08$ ). Results of individual cortisol increments after $\mathrm{ACTH}$ stimulation in the two groups are shown in Figs. $1 A$ (group A) and $1 B$ (group B). The variability of cortisol levels is significantly smaller in group A (difference from the mean at $0 \mathrm{~min}: 32 \pm 11 ; 30 \mathrm{~min}$ : $64 \pm 8 ; 60$ min: $100 \pm 17 \mathrm{nmol} / \mathrm{L})$ compared with group $\mathrm{B}(0$ $\min : 113 \pm 21 ; 30 \mathrm{~min}: 155 \pm 32 ; 60 \mathrm{~min}: 230 \pm 51 \mathrm{nmol} / \mathrm{L}$ ) at all time points studied.

Cortisol levels in group A increase significantly from $178 \pm$ $15 \mathrm{nmol} / \mathrm{L}$ at baseline to $391 \pm 20 \mathrm{nmol} / \mathrm{L}$ and $516 \pm 33$ $\mathrm{nmol} / \mathrm{L}$ at 30 and $60 \mathrm{~min}$, respectively (Fig. $2: p<0.001$ ). In group B cortisol levels increase significantly from $250 \pm 42$ $\mathrm{nmol} / \mathrm{L}$ at baseline to $542 \pm 59 \mathrm{nmol} / \mathrm{L}$ and $733 \pm 89 \mathrm{nmol} / \mathrm{L}$ at 30 and $60 \mathrm{~min}$, respectively (Fig. 2: $p<0.001$ ). Levels of cortisol were significantly lower in group A compared with group B at 30 and 60 min after ACTH stimulation, but not at baseline. Postnatal age was not a significant factor that influenced the cortisol response (repeated measures ANCOVA; $p=$ $0.21)$.

No significant correlation was found between baseline cortisol and the increase in cortisol concentration after stimulation $(r=0.11 ; p=0.62)$.

Response of 17-OHP. The overall effect of gestational age on 17-OHP levels was significant (ANCOVA; $p=0.02$ ), and lower gestational ages were associated with higher 17-OHP levels. The 17-OHP concentration increases significantly from $112 \pm 21 \mathrm{nmol} / \mathrm{L}$ at baseline to $120 \pm 22 \mathrm{nmol} / \mathrm{L}$ at $30 \mathrm{~min}$ and $131 \pm 22 \mathrm{nmol} / \mathrm{L}$ at $60 \mathrm{~min}$ in group A (Fig. 3: $p<0.05$ ). However, no significant increase in 17-OHP levels is found in group B (from $71 \pm 10 \mathrm{nmol} / \mathrm{L}$ at baseline to $80 \pm 10 \mathrm{nmol}$ at $30 \mathrm{~min}$ and $89 \pm 11 \mathrm{nmol} / \mathrm{L}$ at $60 \mathrm{~min}$ ). No significant difference in the level of 17-OHP is found between group A and $\mathrm{B}$ at all time points studied. Postnatal age was not a significant factor that influenced the 17-OHP response (repeated measures ANCOVA; $p=0.68$ ).

Response of the ratio cortisol/17-OHP. The overall effect of gestational age on the ratio cortisol/17-OHP in response to ACTH stimulation was significant (ANCOVA; $p=0.01$ ). The cortisol/17-OHP ratio in group A increases from $2.1 \pm 0.3$ at baseline to $4.2 \pm 0.5$ and $5.1 \pm 0.7$ at 30 and $60 \mathrm{~min}$, respectively (Fig. $4 ; p<0.001$ ). In group $\mathrm{B}$, the cortisol/17OHP ratio increases from $3.6 \pm 0.4$ before ACTH stimulation to $7.1 \pm 0.8$ and $8.6 \pm 1.0$ at 30 and $60 \mathrm{~min}$, respectively (Fig. $4 ; p<0.005)$. The cortisol/17-OHP ratio is significantly higher at all time points in group B compared with group A $(p<$ $0.05)$. The increase in cortisol/17-OHP ratio from baseline to 60 min is significantly higher in group B $(5.0 \pm 0.8)$ compared with group A $(3.0 \pm 0.5)$. Postnatal age was not a significant
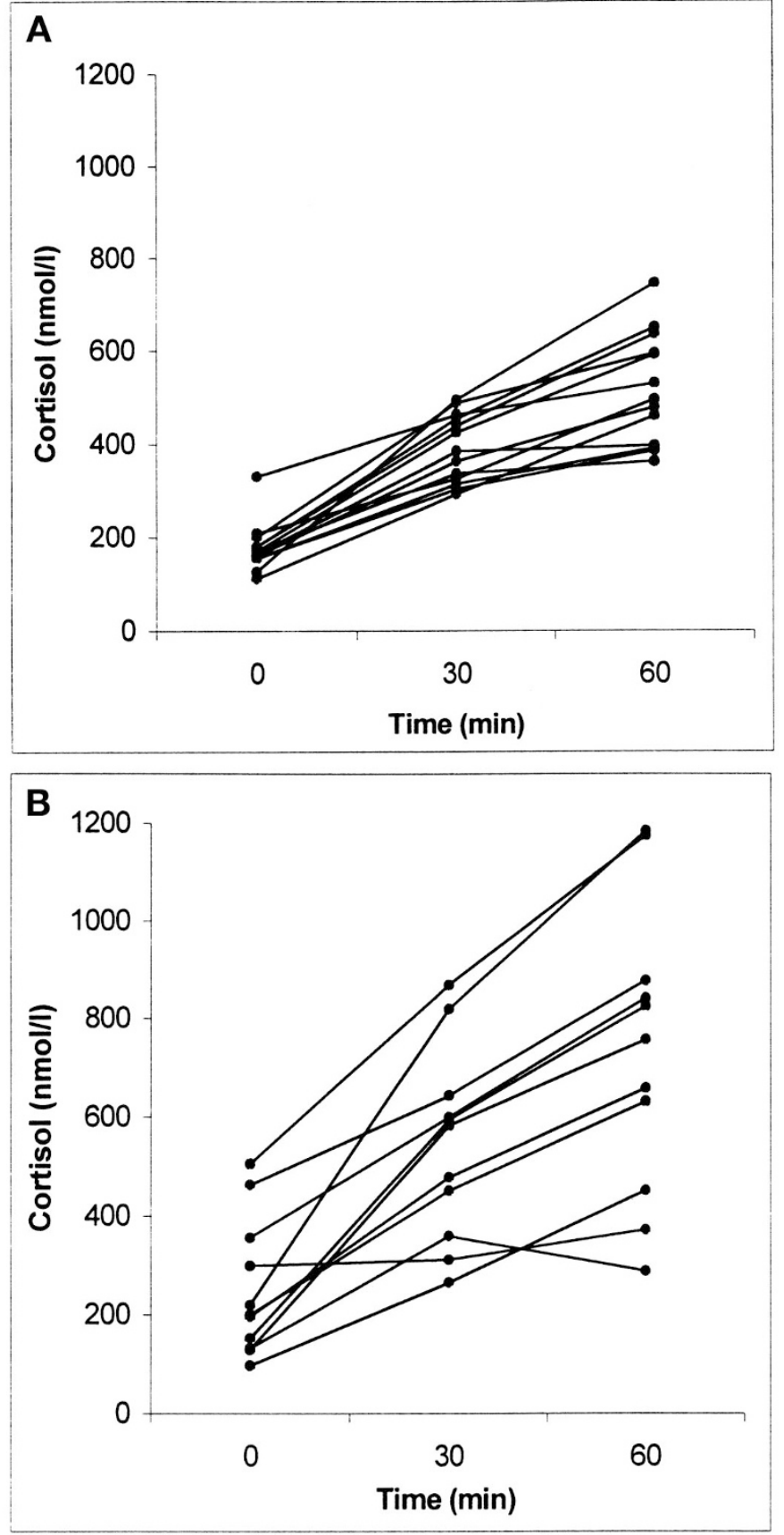

Figure 1. $(A)$ Individual cortisol responses after ACTH stimulation in preterm infants with a gestational age $<30 \mathrm{wk}(n=13)$. (B) Individual cortisol responses after ACTH stimulation in preterm infants with a gestational age between 30 and $33 \mathrm{wk}(n=11)$.

factor that influenced the response of the ratio cortisol/17-OHP (repeated measures ANCOVA; $p=0.45$ ).

Levels of cortisol and cortisone. Cortisone levels were significantly higher in group A $(99.7 \pm 35.2 \mathrm{nmol} / \mathrm{L})$ compared with group B $(64.6 \pm 40.1 \mathrm{nmol} / \mathrm{L} ; p<0.05)$. Cortisol levels determined in the same sample were comparable between group A $(0.05 \pm 0.03 \mu \mathrm{mol} / \mathrm{L})$ and group B $(0.08 \pm 0.05$ $\mu \mathrm{mol} / \mathrm{L})$. No significant correlation was found between cortisol and cortisone levels $(r=0.23 ; p=0.30)$.

Clinical outcome and cortisol response. To study the relation between the maximal cortisol concentration after stimula- 


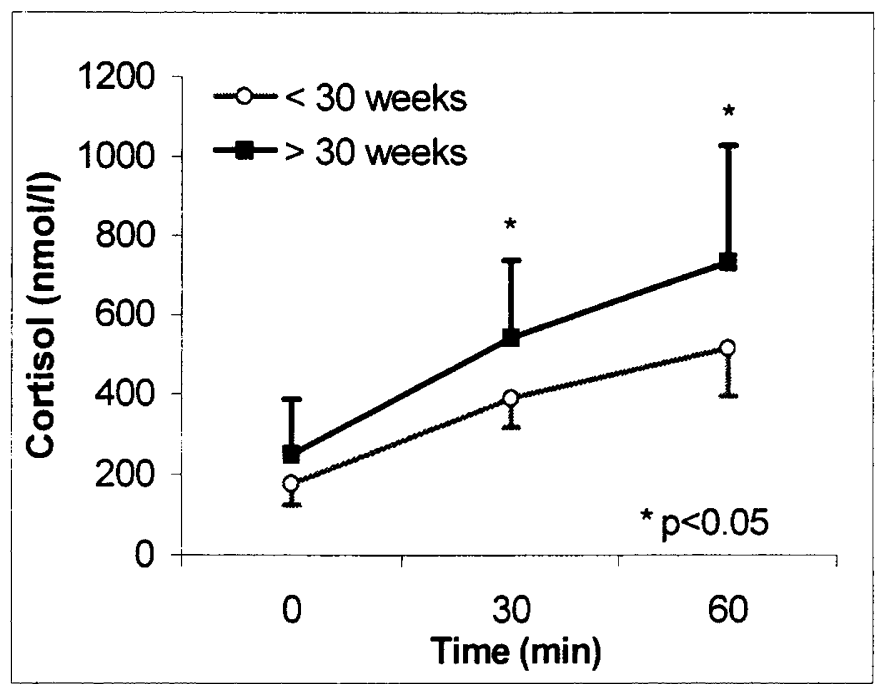

Figure 2. Cortisol concentrations (mean $\pm \mathrm{SD}$ ) in response to ACTH stimulation in infants born $<30 \mathrm{wk}$ of gestation and infants born between $30-33 \mathrm{wk}$ of gestation. Asterisks $\left(^{*}\right)$ indicate a significant difference between the groups $(p<0.05)$.

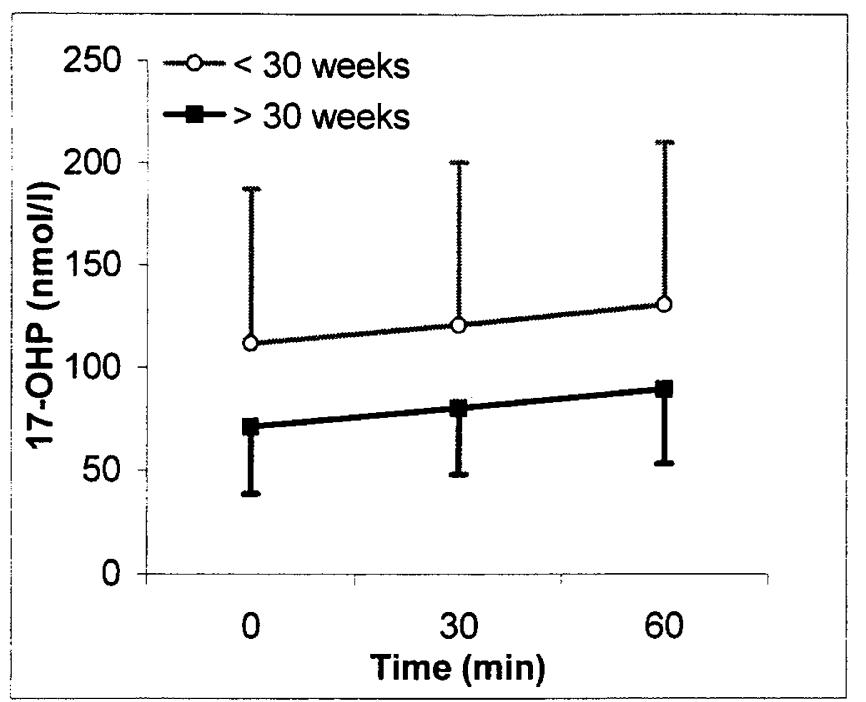

Figure 3. 17-Hydroxyprogesterone concentrations (mean \pm SD) in response to ACTH stimulation in infants born $<30$ wk of gestation and infants born between $30-33$ wk of gestation.

tion and the clinical outcome, the maximal stimulated cortisol concentrations of the infants were divided into three equal groups based on the cortisol concentrations (first group: cortisol $<460 \mathrm{nmol} / \mathrm{L}$; second group: cortisol $460-650 \mathrm{nmol} / \mathrm{L}$; third group: cortisol $>650 \mathrm{nmol} / \mathrm{L}$ ). The group of infants with the lowest stimulated cortisol did not require mechanical ventilation for a longer period of time $(17 \pm 21$ versus $9 \pm 13 ; p$ $=0.35)$ but were admitted to hospital longer $(84.4 \pm 18.7$ versus $41.3 \pm 23.9 ; p<0.05)$ compared with the group of infants with the highest stimulated cortisol. Two infants (one with a gestational age $>30 \mathrm{wk}$ and one $<30 \mathrm{wk}$ ) had stimulated cortisol concentrations below $360 \mathrm{nmol} / \mathrm{L}$. Korte et al. suggested that a cortisol level below $360 \mathrm{nmol} / \mathrm{L}$ indicates an insufficient cortisol secretion in preterm infants (14). However, both these infants had good clinical outcomes and did not show signs of adrenal insufficiency.

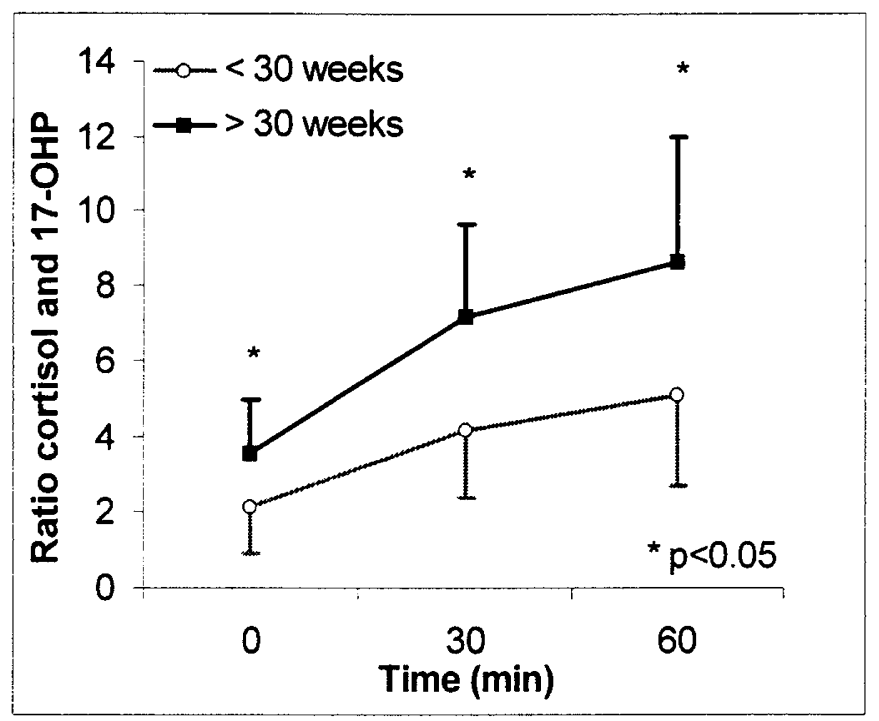

Figure 4. Ratio between cortisol and 17-hydroxyprogesterone (mean \pm SD) in response to ACTH stimulation in infants born $<30 \mathrm{wk}$ and infants born between $30-33 \mathrm{wk}$. Asterisks $(*)$ indicate a significant difference between the groups $(p<0.05)$.

\section{DISCUSSION}

The present study shows that cortisol concentrations increase after stimulation with $1 \mu \mathrm{g} / \mathrm{kg} \mathrm{ACTH}$ in preterm infants born before $33 \mathrm{wk}$ of gestation and that this response is influenced by gestational age. A different response is found between preterm infants with a gestational age below $30 \mathrm{wk}$ and preterms with a gestational age between 30 and $33 \mathrm{wk}$ of gestation. The cortisol levels in infants born before $30 \mathrm{wk}$ of gestation were lower after stimulation and showed less variation compared with more mature preterm infants. These findings suggest that the human adrenal function is not yet fully matured in preterm infants and indicates a decreased capacity for cortisol synthesis and/or a decreased responsiveness to ACTH (15). This may be related to a gradual maturation of the human fetal HPA axis during the third trimester of gestation and is in agreement with the work of Mesiano and Jaffe in primates $(16,17)$. No differences were found in levels of 17-OHP between infants born before $30 \mathrm{wk}$ and infants born after $30 \mathrm{wk}$. The ratio between cortisol and 17-OHP, which represents the ratio between a corticosteroid precursor and cortisol, was significantly lower in infants born before $30 \mathrm{wk}$ of gestation compared with "older" preterm infants. Lower cortisol levels after ACTH stimulation combined with lower cortisol/17-OHP ratios in the extreme preterm infants indicate an insufficient response of the adrenal cortex due to HPA-axis immaturity. The relatively high levels of 17-OHP combined with lower levels of cortisol in the more immature preterm infants suggest a lower activity of adrenal enzymes in their adrenal cortex, for instance 21-hydroxylase and/or $11 \beta$ hydroxylase. Other enzymes such as $11 \beta$-HSD type 1 and 2 , that interconvert cortisone and cortisol, may also influence circulating levels of cortisol. To indirectly estimate the activity of both $11 \beta$-HSD type 1 and 2 , we simultaneously measured cortisone and cortisol concentrations in serum. Preterm infants born before $30 \mathrm{wk}$ of gestation had higher cortisone and similar 
cortisol compared with those born between 30 and $33 \mathrm{wk}$, which suggests a change in activity of $11 \beta$-HSD type 1 and 2 with increasing gestational age. Others have already suggested differences in activity of $11 \beta$-HSD between term and preterm infants, that may be related to relative high levels of $11 \beta$-HSD type 2 in the persisting fetal zone of the adrenal cortex in preterm infants (18). However, since $11 \beta$-HSD type 1 is not only expressed in the adrenal, but also in other tissues including the liver, the amount of circulating cortisone is not solely determined by activity of $11 \beta$-HSD type 1 and 2 in the adrenal cortex. The exact regulation of cortisone and the activity of $11 \beta$-HSD type 1 and 2 remains uncertain in preterm infants and requires further study.

It has been suggested that an immature HPA-axis in preterm infants produces sufficient levels of corticosteroids in unstressed infants, but might be insufficient during stress in case of severe illness when higher levels of cortisol are required (19, 20). In preterm infants an insufficient adrenocortical function may be related to neonatal outcome due to its involvement in the development of chronic lung disease and cardiovascular instability in preterms $(5,6,21-23)$. Previous studies using ACTH stimulation have shown that the HPA-axis in preterm infants functions inadequately compared with term infants (24-26). However, to our knowledge this is the first study showing that the adrenal function of extremely young preterm infants at higher risk for pulmonary morbidity i.e. chronic lung disease is different from "older" preterm infants. Infants born before $30 \mathrm{wk}$ of gestation indeed showed signs of adrenal immaturity and required more mechanical ventilation and were hospitalized for a longer period of time (Table 1). The present study was not designed to establish cut-off values indicative of inadequate adrenal responses in preterm infants in relation to clinical outcome. However, preterm infants with a stimulated cortisol less than $460 \mathrm{nmol} / \mathrm{L}$ (lowest thirtile of cortisol secretion) were admitted to the hospital longer than infants with higher stimulated cortisol concentrations. In children and adults stimulated levels of cortisol below $500 \mathrm{nmol} / \mathrm{L}$ are commonly used to suggest adrenal insufficiency (14). However, a lower level of cortisol of $500 \mathrm{nmol} / \mathrm{L}$ may not be appropriate for very preterm infants and Korte et al. suggested a level of $360 \mathrm{nmol} / \mathrm{L}$ as cut-off value (15). In the present study only two infants had stimulated cortisol concentration less than $360 \mathrm{nmol} / \mathrm{L}$. No data exists regarding the optimal lower limit of cortisol secretion after $1 \mu \mathrm{g} / \mathrm{kg}$ ACTH stimulation in very preterm infants.

Because of the possible relationship between adrenal development and neonatal morbidity in preterm infants, pediatricians, and neonatologists have shown considerable interest in the development of HPA axis in preterms (27). Although a complete understanding of the adrenal cortical function requires the simultaneous determination of several hormones (e.g. dehydroxyepiandosterone sulfate and 11-deoxycortisol), blood sampling in preterm infants is limited by their small blood volume and frequent blood sampling needed during their neonatal intensive care stay.

Traditionally, ACTH stimulation tests in term and preterm infants were performed with high dose ACTH ranging from 36 $\mu \mathrm{g} / \mathrm{kg}$ body weight to $250 \mu \mathrm{g}$ (27-30). The ACTH stimulation test of $1 \mu \mathrm{g}$ has been evaluated in healthy adult volunteers, adult and pediatric patients with suspected or verified endocrine disorders, and in adults, children, and preterm infants treated with steroids $(6,22,31-34)$. Stimulation tests using these lower doses of ACTH have been reported to be more sensitive in detecting insufficient adrenal function in critically ill preterm infants compared with the standard test (22). We found increments of cortisol and 17-OHP in response to 1 $\mu \mathrm{g} / \mathrm{kg}$ ACTH stimulation in the preterm infants studied. Dickstein et al. have shown that doses lower than $1 \mu \mathrm{g}$ fail to induce a significant rise in cortisol in adults (34). However, others have indicated sufficient responses in plasma cortisol with even lower doses $(33,35)$. Because of large differences in body size in neonates, infants, and children it seems reasonable to adjust doses of ACTH to weight or body surface. We have chosen to correct the dose of ACTH for weight because weight measurements are readily available during the 1st week of life, in contrast to length measurements (necessary to calculate body surface).

Some remarks should be made with regard to the technical and practical aspects of an ACTH test. We tried to reduce technical errors that could influence the effect after ACTH stimulation and used freshly prepared ACTH and neonatal indwelling i.v. cannulas without additional plastic tubing. The bioavailability is much lower when ACTH is administered intramuscularly (36). Therefore, especially in "low-dose" ACTH tests i.v. administration is necessary to reach sufficient circulating levels. Some authors have raised concerns about loss of material because of poor i.v. technique resulting in incomplete injection or because of binding of ACTH in plastic giving sets (37).

Several other factors may influence the response after ACTH stimulation in preterm infants. Differences in cortisol and 17-OHP concentrations have been observed earlier between small-for-gestational age (SGA) infants and AGA infants (38, 39). It has also been shown that the cortisol response to ACTH increases in the 1st month of life in preterms compared with the cortisol response directly after birth (28). To minimize the influence of all these factors we studied the effect of a "lower dose" ACTH stimulation test only in AGA preterm infants born before $33 \mathrm{wk}$ of gestation between d 5 and 10 after birth. Furthermore, antenatal steroids administered to mothers at risk of preterm birth may suppress the HPA axis in preterms directly after birth but not after the 1st week of life (40). Exclusion of preterm infants who did not receive antenatal glucocorticoid treatment from the study did not significantly change the results [data not shown]. With respect to the small number of infants not treated with antenatal glucocorticoids, the present study does not provide information on the suppressive or nonsuppressive effect of antenatal steroids on the function of the HPA axis in preterm infants after birth.

\section{CONCLUSION}

In conclusion, the effect of gestational age on the response to ACTH stimulation and the different response to ACTH stimulation in preterm infants born before $30 \mathrm{wk}$ of gestation compared with preterms born between 30 and 33 wk of ges- 
tation indicate a gradual maturation of the HPA-axis during the third trimester of gestation. This suggests that the HPA-axis function may be immature in infants before term which is expressed by decreased cortisol synthesis and/or a decreased responsiveness to ACTH. A difference in the ratio of cortisol and a cortisol precursor, 17-OHP, suggest an immaturity of enzymes in the adrenal cortex that are necessary for the production of cortisol. The lower levels of cortisol after ACTH stimulation found in preterms with a gestational age below 30 wk indicate that the adrenal cortex in these infants may inadequately respond to stress, which may contribute to the high rate of pulmonary and circulatory morbidity in these infants compared with older preterms $(41,42)$. The low-dose ACTH test could be a valuable tool in assessing the HPA-axis in sick very preterms (40). However, care should be taken to perform the test technically correct in well-defined pediatric or neonatal populations with as few confounding factors as possible.

\section{REFERENCES}

1. Liggins GC 1994 Fetal lung maturation. Aust N Z J Obstet Gynaecol 34:247-250

2. Brooks AN, Hagan DM, Howe DC 1996 Neuroendocrine regulation of pituitaryadrenal function during fetal life. Eur J Endocrinol 135:153-165

3. Wallace AM, Beesley J, Thomson M, Giles CA, Ross M, Taylor NF 1987 Adrenal status during the first month of life in mature and premature human infants. J Endocrinol 112:473-480

4. Midgley PC, Russell K, Oates N, Holownia P, Shaw JCL, Honour JW 1998 Adrenal function in preterm infants: ACTH may not be the sole regulator of the fetal zone. Pediatr Res 44:887-893

5. Helbrock HJ, Insoft RM, Conte FA 1993 Glucocorticoid-responsive hypotension in extremely low birth weight newborns. Pediatrics 92:715-717

6. Watterberg KL, Scott SM 1995 Evidence of early adrenal insufficiency in babies who develop bronchopulmonary dysplasia. Pediatrics 95:120-125

7. Merz U, Pfäffle R, Peschgens Th, Hörnchen H 1998 The hypothalamic-pituitaryadrenal axis in preterm infants weighing $<1250$ gram: association with perinatal data and chronic lung disease. Acta Pediatr 87:313-317

8. Wood JB, James VHT, Frankland AW, Landon J 1965 A rapid test of adrenal function. Lancet 243:525-531

9. Thaler LM, Blevins LS 1998 The low dose (1-mg) adrenocorticotropin stimulation test in the evaluation of patients with suspected central adrenal insufficiency. J Clin Endocrinol Metab 83:2726-2729

10. Tjordman K, Jaffe A, Trostanetsky Y, Greenman Y, Limor R, Stern N 2000 Low-dose $(1 \mathrm{mg})$ adrenocorticotrophin (ACTH) stimulation as a screening test for impaired hypothalamo-pituitary-adrenal axis function: sensitivity, specificity and accuracy in comparison with the high-dose $(250 \mathrm{mg})$ test Clin Endocrinol 52:633-640

11. Kloosterman GJ On intrauterine growth. the significance of prenatal care 1970 Int J Gynecol Obstet 8:895-912

12. Wong T, Shackleton CHL, Covey TR, Ellis G 1992 Identification of the steroids in neonatal plasma that interfere with 17 alpha-hydroxyprogesterone radioimmunoassays. Clin Chem 38:1830-1837

13. Meulenberg PMM, Ross HA, Swinkels LMJW, Benraad ThJ 1987 The effect of oral contraceptives on plasma-free and salivary cortisol and cortisone. Clin Chem Acta $165: 379-385$

14. Korte C, Styne D, Merritt A, Mayes D, Wertz A, Helbock H J 1996 Adrenocortical function in the very low birth weight infant: improved testing sensitivity and association with neonatal outcome. J Pediatr 128:257-263

15. Karlsson R, Kallio J, Toppari J, Scheinin M, Kero P 2000 Antenatal and early postnatal dexamethasone treatment decreases cortisol secretion in preterm infants. Hormone Res 53:170-176
16. Jaffe RB, Mesiano S, Smith R, Coulter CL, Speneer SJ, Chakravorty A 1998 The regulation and role of fetal adrenal development in human pregnancy. Endocr Res 24:919-926

17. Mesiano S, Jaffe RB 1997 Development and functional biology of the primate fetal adrenal cortex. Endocr Rev 18:378-403

18. Fujitaka M, Jinno K, Sakura N, Takata K, Yamasaki T, Inada J, Sakano T, Horino N, Kidani K, Ueda K 1997 Serum concentrations of cortisone and cortisol in premature infants. Metabolism 46:518-521

19. Lee MM, Rajagopalan L, Berg GJ, Moshang T 1989 Serum adrenal steroid concentrations in premature infants. J Clin Endocrinol Metab 69:1133-1136

20. Saedi S al, Dean H, Dent W, Cronin C 1995 Reference ranges for serum cortisol and 17-hydroxyprogesterone levels in preterm infants. J Pediatr 126:985-987

21. Ward RM, Kimura RE, Rich-Denson C 1991 Addisonian crisis in extremely premature neonates. Clin Res 39:11a

22. Korte C, Styne D, Merritt A, Mayes D, Wertz A, Helbock HJ 1996 Adrenocortical function in the very low birth weight infant: improved testing sensitivity and association with neonatal outcome. J Pediatr 128:257-263

23. Gaissmaier RE, Pohlandt F 1999 Single dose dexamethasone treatment of hypotension in preterm infants. J Pediatr 134:701-705

24. Hingre RV, Gross SJ, Hingre KS, Mayes DM, Richman RA 1994 Adrenal steroidogenesis in very low birth weight preterm infants. J Clin Endocrinol Metab 78:266270

25. Scott SM, Watterberg K 1995 Effect of gestational age, postnatal age, and illness on plasma cortisol concentrations in premature infants. Pediatr Res 37:112-116

26. Jett PJ, Samuels MH, McDaniel PA, Benda GI, Lafranchi SH, Reynolds JW, Hanna CF 1997 Variability of plasma cortisol levels in extremely low birth weight infants. J Clin Endocrinol Metab 82:2921-2925

27. Ng PC 2000 The fetal and neonatal hypothalamic-pituitary-adrenal axis. Arch Dis Child 82:F250-F254

28. Noguchi A, Reynolds JW 1978 Serum cortisol and dehydroepiandrosterone sulfate responses to adrenocorticotropin stimulation in premature infants. Pediatr Res 12:1057-1061

29. Thomas S, Murphy JF, Dyas J, Ryalls M, Hughes IA 1986 Response to ACTH in the newborn. Arch Dis Child 61:57-60

30. Hanna CE, Keith LD, Colasurdo MA, Bufflein DC, Laird MR, Mandel SH, Cook DM, Lafranchi SH, Reynolds JW 1993 Hypothalamic pituitary adrenal function in the extremely low birth weight infant. J Clin Endocrinol Metab 76:384-387

31. Alkalay AL, Klein AH, Nagel RA, Pomerance JJ 1996 Evaluation of hypothalamicpituitary-adrenal axis in premature infants treated with dexamethasone. Am J Perinatol 13:473-477

32. Karlsson R, Kallio J, Toppari J, Kero P 1999 Timing of peak serum cortisol values in preterm infants in low-dose and the standard ACTH test. Pediatr Res 45:367-369

33. Bridges NA, Hindmarsh PC, Pringle PJ, Honour JW, Brook CG 1998 Cortisol, androstenedione (A4), dehydroepiandrosterone sulphate (DHEAS) and 17 hydroxyprogesterone (17OHP) responses to low doses of (1-24)ACTH. J Clin Endocrinol Metab 83:3750-3753

34. Dickstein G, Spigel D, Arad E, Shechner C 1997 One microgram is the lowest ACTH dose to cause a maximal cortisol response. There is no diurnal variation of cortisol response to submaximal ACTH stimulation. Eur J Endocrinol 137:172-175

35. Daidoh H, Morita H, Mune T, Murayama M, Hanafusa J, Ni H, Shibata H, Yasuda K 1995 Responses of plasma adrenocortical steroids to low dose ACTH in normal subjects. Clin Endocrinol 43:311-315

36. Wuthrich P, Martenet M, Buri P 1994 Effect of formulation additives upon the intranasal bioavailability of a peptide drug: Tetracosactide. Pharm Res 11:278-282

37. Murphy H, Livesey J, Espiner EA, Donald RA 1998 The low dose ACTH test - a further word of caution. J Clin Endocrinol Metab 83:712-713

38. Economides DL, Nicolaides KH, Linton EA, Perry LA, Chard T 1988 Plasma cortisol and adrenocorticotropin in appropriate and small for gestational age fetuses. Fetal Therapy 3:158-164

39. Doerr HG, Versmold HT, Bidlingmaier F, Sippill WG 1989 Adrenocortical steroids in small-for-gestational-age term infants during the early neonatal period. Pediatr Res 25:115-118

40. Ng PC, Wong GWK, Lam CWK 1997 Pituitary-adrenal response in preterm very low birth weight infants after treatment with antenatal corticosteroids. J Clin Endocrinol Metab 82:3548-3552

41. Watterberg KL, Gerdes JS, Gifford KL, Lin H-M 1999 Prophylaxis against early adrenal insufficiency to prevent chronic lung disease in premature infants. Pediatr 104:1258-1263

42. Huysman MWA, Hokken-Koelega ACS, Ridder MAJ de, Sauer PJJ 2000 Adrenal function in sick very preterm infants. Pediatr Res 48:629-633 